\title{
Notch in Memories: Points to Remember
}

\author{
Swananda Marathe and Lavinia Alberi*
}

\begin{abstract}
Memory is a temporally evolving molecular and structural process, which involves changes from local synapses to complex neural networks. There is increasing evidence for an involvement of developmental pathways in regulating synaptic communication in the adult nervous system. Notch signaling has been implicated in memory formation in a variety of species. Nevertheless, the mechanism of Notch underlying memory consolidation remains poorly understood. In this commentary, besides offering an overview of the advances in the field of Notch in memory, we highlight some of the weaknesses of the studies and attempt to cast light on the apparent discrepancies on the role of Notch in memory. We believe that future studies, employing high-throughput technologies and targeted Notch loss and gain of function animal models, will reveal the mechanisms of Notch dependent plasticity and resolve whether this signaling pathway is implicated in the cognitive deficit associated with dementia. () 2015 Wiley Periodicals, Inc.
\end{abstract}

KEY WORDS: notch; memory; hippocampus; amygdala; sleep

\section{INTRODUCTION}

In the past decade, several studies have implicated developmental pathways in the regulation of synaptic plasticity and memory processing. Among these, the Notch pathway has gained increasing attention. Notch is a transmembrane receptor with transcriptional and non-transcriptional signaling potential. Notch functions as a modulator of synaptic transmission and behavior in the adult brain. In this opinion article, we aim to shed light on the role of Notch signaling in memory formation and consolidation taking into consideration the existing studies in a variety of animal models.

Department of Medicine, Institute of Anatomy, University of Fribourg, Fribourg, Switzerland

Grant sponsor: Swiss National Foundation; Synapsis Foundation Switzerland for Alzheimer's Disease Research.

Abbreviations used: AD, Alzheimer's disease; CBP, CREB binding protein; UPS, ubiquitin proteasomal system

*Correspondence to: Lavinia Alberi, Institute of Anatomy, Department of Medicine, University of Fribourg, Fribourg, Switzerland. E-mail: lavinia. alberi@unifr.ch

\section{MECHANISMS GOVERNING MEMORY}

Learning and memory are highly conserved neural processes which are essential for the animal's survival and reproduction. During a life span, sensory experiences can be stored in memory which can last for minutes, hours or years depending on the temporal resolution and dynamic molecular changes. Mechanistically, sensitization of neuronal networks upon sensory experience in behaving animals can produce transient post-translational modifications of preexisting proteins at the synapse which last from minutes to hours (short-term or working memory). On the other hand, enhanced sensory exposure, through a single learning trial or repetitive drills, causes de novo protein synthesis leading to synaptic strengthening which can last for years (long-term memory). In the time window of 30 minutes to $24 \mathrm{~h}$ following learning, the establishment of memory traces is thought to happen in two phases involving 1) local molecular and structural changes at single synapses, through Hebbian plasticity (cellular correlates are long-term potentiation (LTP) and long-term depression (LTD)) and 2) strengthening of synaptic connections in the memory ensemble in a process called synaptic scaling. How this phase transition occurs is still poorly understood but it appears to require sleep (Frank, 2012). In the first phase of synaptic potentiation, the "molecular pool of memories" is acquired through gene transcription (Alberini, 2009) and RNA translation (Gal-BenAri et al., 2012). Later, epigenetic modifications such as RNA interference (Saab and Mansuy, 2014) and ubiquitin proteasomal system (UPS) degradation (Fustiñana et al., 2014) weigh out the optimal molecular balance for the establishment of the memory reservoir. Altogether, these molecular alterations contribute to synaptic remodeling of neuronal connections within the memory engram (Caroni et al., 2012) (Fig. 1). In this context, cellular communication cascades, which act beyond neurotransmitter release, can strengthen the synaptic network through intracellular mediators and gene targets. Among these, neurodevelopmental signaling pathways such as Reelin (Herz and Chen, 2006), Wnt (Oliva et al., 2013) and Notch (Alberi et al., 2013) transduce signals which are instrumental 


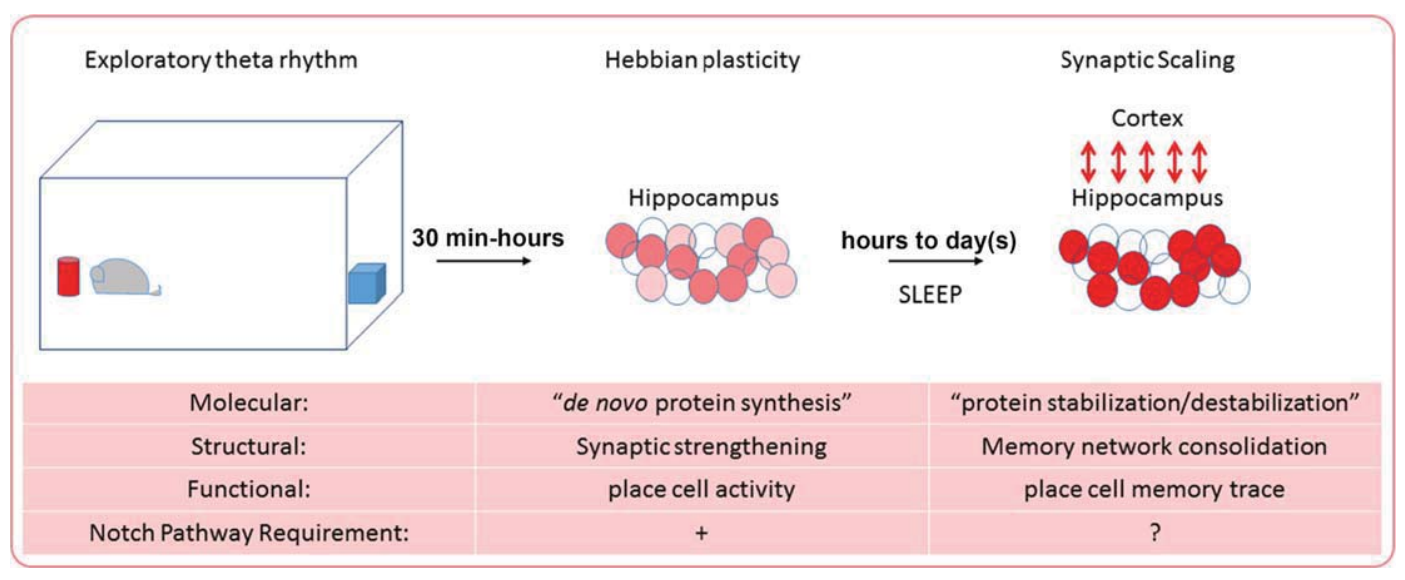

FIGURE 1. Scheme depicting the progression and establishment of long-term memory. Hippocampus dependent spatial memory is encoded in two steps. During spatial learning, the exploratory theta oscillations in the hippocampal network are associated with a concomitant place cell spiking activity. The place cells are thought to play a crucial role in encoding spatial information. At a cellular level, memory acquisition is known to involve de novo protein synthesis, which is shown to be essential for activity-dependent Hebbian plasticity events such as LTP at individual synapses. Notch signaling has been shown to be essen- tial for induction of LTP as well as spatial memory acquisition. During subsequent sleep, synchronized high frequency ripples in the hippocampal networks are associated with replay of the place cell activity. Also, during sleep, synchronous activity between the hippocampus and cortex has been thought to underlie information transfer from the hippocampus to the cortex for long-term memory storage. The role of Notch pathway during these latter processes remains ambiguous. [Color figure can be viewed in the online issue, which is available at wileyonlinelibrary.com.] for memory. How these pathways are modulated and contribute to the evolution of memory is a subject of intense study.

\section{NOTCH IN THE ADULT BRAIN}

In the mammalian brain, Notch1 and Jagged1 appear to be the relevant receptor and ligand respectively (Alberi et al., 2011; Sargin et al., 2013). Notch2 is also expressed in neurons but levels are considerably lower as compared to Notch1 in physiological conditions (Ferrari Toninelli et al., 2003). Notch1 is a transmembrane receptor, which acquires nuclear signaling potential after ligand-induced sequential cleavages (Berezovska et al., 1998). The intracellular portion of the Notch1 receptor (NICD1) translocates to the nucleus and binds to the transcription factor, RBPJK, to induce transcription of downstream targets (canonical signaling) (Fig. 2). At present, the number of confirmed targets in neurons is limited to the Hes genes (Stump et al., 2002) but it is expected to expand in the near future, using genome-wide technology as previously shown in immune cells and neuronal progenitors (Wang et al., 2011; Li et al., 2012; Trimarchi et al., 2014). Moreover, Notch1 can act in a non-transcriptional (non-canonical) fashion through the interaction with kinases (PKC and Abl) (Giniger, 1998; Song and Giniger, 2011; Zhang et al., 2013) or adhesion molecules (Klingon)(Matsuno et al., 2009) to mediate neural plasticity changes (Fig. 2).

Notch pathway components are expressed in sensory networks from worms to humans (Berezovska et al., 1998; Bere- zovska et al., 1999; Ge et al., 2004; Presente et al., 2004; Chao et al., 2005). Intriguingly, in aging (Placanica et al., 2009) and Alzheimer's disease (AD) (Berezovska et al., 1998; Steiner et al., 2008), conditions in which Notch1 alteration have been reported, sensory functions are affected early on. This suggests a possible role of this signaling pathway in the neural transmission deficits. Indeed, the ligand and the Notch receptor appear juxtaposed in complementary neuronal compartments in worms (Singh et al., 2011), Drosophila (Lieber et al., 2011) and rodents (Alberi et al., 2011; Brai et al., 2014) supporting the recruitment of Notch signaling upon neuronal stimulation (Alberi et al., 2011; Lieber et al., 2011). This directional positioning of ligand and receptor also underlies the activitydependent processing of Notch through $\gamma$-secretase (Alberi et al., 2011). Therefore, familial mutations in human Presenilins of the $\gamma$-secretase complex (Steiner et al., 1999; Moehlmann et al., 2002) and alteration in $\gamma$-secretase trafficking through loss of Arc/Arg3.1 (Wu et al., 2011) can affect Notch processing independently of ligand availability (Alberi et al., 2011). This emphasizes the importance of $\gamma$-secretase function as the limiting step for Notch activation in neurons (De Strooper et al., 1999) and favors the hypothesis that alterations in Presenilins, as observed in familial AD, may also affect Notch signaling contributing to the pathophysiology of the disease.

In addition to the activity-dependent Notch processing, there is increasing evidence for Notch1 signaling changes in different phases of memory processing. In the memory formation phase, following spatial learning, Notch 1 expression and activation is rapidly induced in hippocampal CA field ensembles and lasts for up to $8 \mathrm{~h}$, coinciding with the phase of 

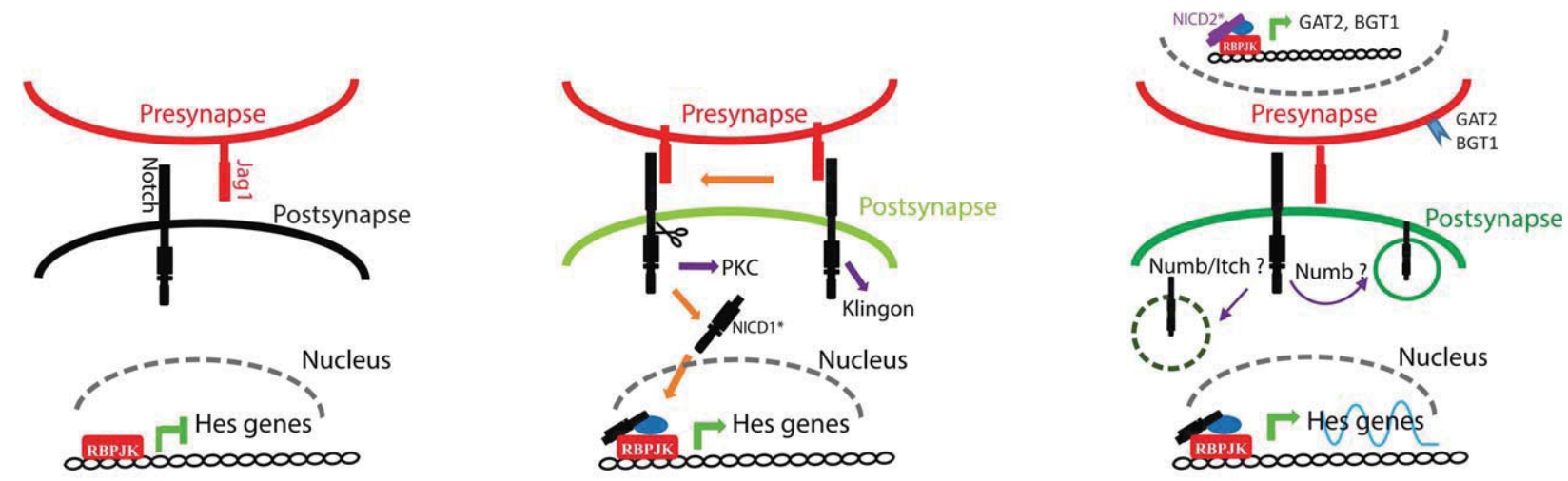

Naive

\begin{tabular}{l|l} 
Learning & memory formation
\end{tabular}

memory consolidation

FIGURE 2. Known and potential mechanisms of Notch in memory encoding. Notch1 (black transmembrane protein) and Jagged1 (red transmembrane protein) are expressed at the synapse and their expression is regulated by synaptic activity. In naive mice (blue bar), Notch1 and Jagged 1 are kept at relatively low levels. Increased correlated neuronal activity following single trial learning (yellow bar), augments Notch1 expression, processing (scissors), activation (NICD1) and transcriptional signaling through RBPJK and non-transcriptional signaling through PKC or Klingon from the period of memory formation (green light bar) extending to the time of memory consolidation (green dark

memory consolidation (Alberi et al., 2011) (Fig. 2). The induction of Notch1 protein in the consolidation phase of memory has also been observed in the dentate gyrus of rats, $12 \mathrm{~h}$ following passive avoidance training. Nevertheless, the increase in Notch1 receptor was interpreted as a readout of protein accumulation since Notch signaling appeared to be repressed based on the downregulation of Hes1 transcription (Conboy et al., 2007). The analysis of Hes1 targets is unfortunately restricted to the $12 \mathrm{~h}$ time point, leaving the reader wondering whether, at this time, the expression of Hes 1 results form a trough in Hes1 oscillations (Kageyama et al., 2008) or whether canonical signaling is shunted. Yet, the authors do not investigate this possibility and suggest that, downregulation of Notch signaling, concomitant to the upregulation of Wnt signaling, promotes the integration of newly formed synapses in the memory circuit (Conboy et al., 2007). However, in light of more recent work, the accumulation of Notch1 hints to a reduction in Itch and Numb-mediated degradation of Notch (McGill et al., 2009) and increased Numb isoform-dependent protein recycling (Kyriazis et al., 2008). Interestingly, ubiquitin-mediated proteolysis (Fioravante and Byrne, 2011) and receptor endocytosis (Shepherd et al., 2006), occurring during the memory consolidation period, appear to be essential mechanisms for synaptic scaling. Thus, at this stage, Numb, which also actively contributes to spine remodeling (Nishimura et al., 2006), may be a strong candidate in sorting Notch1 at strengthened synapses (Fig. 2). In this setting, Notch1 and Jagged1 transcripts downregulation, and degradation of NICD1 (Conboy et al., 2007) would be adopted to prevent potentially toxic nuclear signaling bar). In this setting, Notch1 has been shown to contribute to synaptic potentiation (light green postsynaptic membrane). In later phases of memory consolidation, Notch signaling may enter an oscillatory phase through the Hes genes. Notch 1 protein may be still tagged at the synaptic membrane (green membrane) and undergo either recycling (Numb) or endocytosis-mediated degradation (Numb/Itch). On the presynaptic side (red membrane), RBPJK signaling regulates expression of the GABA transporter GAT2 and BGT1. This event likely happens under regulation of NICD2. [Color figure can be viewed in the online issue, which is available at wileyonlinelibrary.com.]

(Arumugam et al., 2006; Alberi et al., 2010). Whether, in this or later phases, a similar regulation of Notch activity takes place in the CA fields, encoding for spatial memory, remains to be explored. Interestingly, we observed that, after a 5 days T-maze training paradigm, Notch1 transcript and protein are significantly reduced in the hippocampus whereas expression of Notch1 is considerably augmented in the somatosensory cortex (unpublished data Alberi L.). It has been previously shown that in the memory reconsolidation phase, after repetitive training, there is a disproportion in genes downregulation as opposed to the memory acquisition phase (Miyashita et al., 2008). It is likely that, in rounds of memory recall, RNA/protein destabilization and stabilization events by weakening Notch signaling requirement in the hippocampus (Costa et al., 2003; Alberi et al., 2011) sharpen the memory trace.

Another recent report using cued fear learning has shown that Notch1 transcript expression is actively downregulated in the amygdala by miRNA34a interference after cued learning (2 and $6 \mathrm{~h}$ ) (Dias et al., 2014). Although the authors do not confirm a reduction in Notch1 receptor, they assume that decreased transcript indicates less protein and signaling. Still, granting that cued learning causes a decrease in Notch signaling, this report is in net contrast with our studies showing that spatial learning induces Notch signaling in a comparable time window (1.5-8 h) (Alberi et al., 2011). It remains possible that contextual and cued learning engage different molecular mechanisms, yet it is essential to remember that in contrast to the CA field, less than $20 \%$ of the lateral amygdala neurons are recruited in memory encoding after cued learning (Han et al., 
TABLE 1.

Studies reporting a direct involvement of Notch signaling in animal behavior.

\begin{tabular}{|c|c|c|c|c|c|}
\hline $\begin{array}{l}\text { Animal } \\
\text { model }\end{array}$ & Gene & $\begin{array}{l}\text { Neuron type } \\
\text { or brain region }\end{array}$ & Expression & Behavior & Reference \\
\hline C. elegans & Lin12 & Head interneurons & $\uparrow$ & Reversal behavior & (Chao et al., 2005) \\
\hline C. elegans & $\operatorname{Lin} 12$ & Head interneurons & $\uparrow$ & $\begin{array}{l}\text { Octanol avoidance and increased } \\
\text { arousal/quiescence }\end{array}$ & (Singh et al., 2011) \\
\hline C. elegans & GLP-1 & Head ciliated sensory neurons & $\uparrow$ & Increased arousal/quiescence & (Singh et al., 2011) \\
\hline Drosophila & Notch & Mushroom bodies & $\uparrow$ & Long-term memory & $\begin{array}{l}\text { (Ge et al., 2004; } \\
\text { Presente et al., 2004) }\end{array}$ \\
\hline Drosophila & Notch & Whole brain & $\uparrow$ & Long-term memory & (Zhang et al., 2013) \\
\hline Drosophila & Notch & Mushroom bodies & $\uparrow$ & Sleep/learning & (Seugnet et al., 2011) \\
\hline Drosophila & $\mathrm{Su}(\mathrm{H})$ & Mushroom bodies & $\uparrow$ & Long-term memory & (Song et al., 2009) \\
\hline Mouse & Notch1 & Hippocampus & $\uparrow$ & Learning/memory formation & $\begin{array}{l}\text { (Costa et al., 2003; } \\
\quad \text { Alberi et al., 2011) }\end{array}$ \\
\hline Rat & Notch1 & Dentate gyrus & $\uparrow$ & Learning/memory formation & (Conboy et al., 2007) \\
\hline Rat & Notch1 & Dentate gyrus & $\downarrow$ & Memory recall & (Conboy et al., 2007) \\
\hline Mouse & Notch1 & Amygdala & $\downarrow$ & Cued fear learning & (Dias et al., 2014) \\
\hline Mouse & Jagged1 & Hippocampus & $\uparrow$ & Learning/memory formation & (Sargin et al., 2013) \\
\hline Mouse & $\begin{array}{c}\text { Mind bomb1 } \\
\text { (Notch activation) }\end{array}$ & Hippocampus & $\uparrow$ & Long-term memory & (Yoon et al., 2012) \\
\hline Mouse & NICD1 & Visual cortex & $\uparrow$ & Reduced visual acuity & (Dahlhaus et al., 2008) \\
\hline Mouse & Notch1 & Olfactory bulb & $\uparrow$ & Olfaction & (Brai et al., 2014) \\
\hline
\end{tabular}

Lin-12: Notch homolog receptor (C. elegans); GLP1: Notch homolog receptor (C. elegans); Su(H): RBPJK homolog (Drosophila); NICD1: Notch1 intracellular domain.

2007) and $10 \%$ of the neurons in the amygdala express the immediate gene Arc following fear conditioning (Young and Williams, 2013).Therefore, in regions of sparse coding, the visualization/quantitation of Notch expression and signaling in activated neurons, i.e. through the use of destabilized Notch reporter constructs (Marathe and Alberi, 2014), is essential to avoid confounding effects from the most abundant silent neuronal population. Based on this, it cannot be excluded that in the study of Dias the changes observed are a readout of this inactive counterpart.

On the whole, it appears that over time Notch1 is differentially regulated after learning. Understanding the temporal dynamicsô of Notch1 transcript modulation, Notch1 protein translation, ubiquitination and trafficking will cast light on the regulation and role of Notch signaling in the maturation of memories.

\section{NOTCH SIGNALING IN MEMORY AND ANIMAL} BEHAVIOR

Several works have indicated a significant involvement of Notch in animal behavior (Table 1). From all these studies, it emerges that Notch has an instrumental function in mediating neural responses and memory processing. However, how Notch canonical signaling contributes to Notch1 function in neurons remains a matter of debate. Early work has indicated that RBPJK $+/-$ mice display a milder but significant spatial memory acquisition defect as compared to Notch1 +/(Costa et al., 2005). A more recent study, in Drosophila, attributes to the homolog of $\mathrm{RBPJK}, \mathrm{Su}(\mathrm{H})$, the same properties as Notch in long-term memory (Song et al., 2009). In contrast, a subsequent work in mice has indicated that the loss of RBPJK in mature excitatory networks does not recapitulate the effect of Notch1 loss of function in spatial memory (Sato et al., 2012). One of the latest studies investigating the role of RBPJK in synaptic plasticity has found that another $\mathrm{RBPJKcKO}$ mouse model displays a short- as well as a longterm spatial memory impairment comparable to the Notch1cKO suggesting that canonical signaling takes place in both memory formation and consolidation (Fig. 2). Nevertheless, in contrast to the Notch1cKOs, the plasticity deficits, in the RBPJKcKOs, derive from increased postsynaptic inhibition through interference with GABA uptake transporters at the presynaptic terminal (Liu et al., in press). This work is intriguing and proposes a unique presynaptic role for RBPJK most probably through Notch2. Despite the redundancy in canonical signaling modality of Notch1 and Notch2 (Ong et al., 2006) and their cooperative function in limb development (Pan et al., 2005), there is increasing evidence that the two heterologous receptors can activate distinct target genes (Fan et al., 2004). 
Divergent Notch1 and Notch2 exert distinct functions in kidney development (Cheng et al., 2007) and display opposite effects on tumor growth (Fan et al., 2004; Parr et al., 2004). Therefore, it is conceivable that, in addition to the postsynaptic role of Notch1, presynaptic Notch2, by facilitating inhibition, contributes to quantal synaptic scaling (Erickson et al., 2006). Moreover, since Notch2 levels in neurons are subthreshold, at basal level, it would be interesting to know whether with increased synaptic transmission through Notch1, Notch2 levels rise to drive canonical signaling presynaptically.

Despite this last notable advancement, our understanding of canonical Notch signaling in the adult brain remains far from complete. A recent work has shown that overexpression of the canonical Notch target Hes1 before training, impairs memory retrieval in a cued fear conditioning test (Dias et al., 2014). Even if in the amygdala canonical signaling interferes with memory consolidation, it is surprising that in the paper of Sato or Liu, no increase in contextual or cued fear memory (Sato et al., 2012; Liu et al., in press) was observed. In addition, overexpression of Hes 1 represents an additional caveat. In fact, sustained Hes1 activity has been shown to inhibit Notch signaling by abolishing Hes1's oscillatory activity, which is instrumental for proliferation and neuronal stem cell maintenance (Kageyama et al., 2008). If Hes1 oscillatory activity occurs also in neurons, overexpression of Hes 1 may hamper the orchestration of signaling molecules leading to a dominant negative effect on memory retrieval. This interference should also be taken into consideration when interpreting the effect of sustained in vivo Notch1 activation, which leads to persistent Hes1 overexpression with concomitant amnesia (Conboy et al., 2007). Indeed, a work using targeted mild overexpression of NICD1 in cortical pyramidal neurons has shown a significant reduction in mature dendritic spines, a dramatic shrinkage of the cell bodies and a concomitant deficit in cortical synaptic plasticity (Dahlhaus et al., 2008). In the worst case scenario, Notch1 overexpression in neurons can induce cell death (Arumugam et al., 2011). Thus, based on the current knowledge, the use of gain of function strategies for Notch activity pose a serious challenge for interpretation.

That said, since Notch has transcriptional and nontranscriptional signaling activity, it is possible that these signaling modalities are differentially recruited in the acquisition and retrieval phase, and that downregulation of Notch canonical signaling is required at a specific stage of memory consolidation. In support of the hypothesis of bimodal signaling in different phases of memory, it has been previously shown that CREB can display its functions in memory formation and consolidation through activation of early immediate genes, such as c-fos, and late response genes, such as C/EBP, respectively (Alberini, 2009). Interestingly, the transcriptional coactivator of CREB, CREB binding protein (CBP), was identified by in silico analysis as a canonical target of Notch (Saura et al., 2004), establishing for the first time a connection between Notch and CREB signaling. A more recent work in Drosophila, has indicated a further noncanonical interaction between Notch and CREB activity in long-term memory (Zhang et al., 2013). Previously, another non- canonical interaction functional in memory formation was identified between Notch and the adhesion molecule Klingon (Matsuno et al., 2009) supporting the idea that non-canonical mechanisms are essential for neuronal connectivity (Giniger, 2012). Despite these reports in Drosophila, it remains largely unresolved whether and which canonical or non-canonical mechanisms of Notch contribute to different aspects of memory in mammals. Further studies dissecting these canonical versus noncanonical mechanisms will help reconcile the present discrepancies on the differential recruitment of Notch in memory.

\section{HYPOTHESIS OF CIRCADIAN NOTCH1 IN MEMORY}

Sleep has been shown to be essential for memory consolidation after learning. It is known that during sleep, place cell activity is replayed in the same temporal sequence as during the spatial learning session undergone before sleep (O'Neill et al., 2010). Notch is induced in place cells upon learning, where it is thought to contribute to synaptic potentiation (Wang et al., 2004; Alberi et al., 2011). It is possible that waves of Notch activity during sleep through potentiation and depotentiation processes may stabilize the memory engram and contribute to the information transfer to cortical structures. Indeed, it is thought that sleep allows the conversion from Hebbian plasticity at local synapses to a more global synaptic scaling which contributes to network remodeling (Frank, 2012). The recent studies in C. elegans and Drosophila pointing out a role of Notch in sleep/quiescence remain to be confirmed in mammals, but suggest that this pathway may also be involved in the memory reorganization during quiescence (Seugnet et al., 2011; Singh et al., 2011). Adding to the requirement of Notch 1 in memory, in $C$. elegans this signaling pathway displays paradoxical effects in inducing quiescence. Singh and colleagues carefully investigated this effect by studying the gain and loss of function models for Notch activity in interneurons and ciliated neurons. They observed that gain of function of Notch induces quiescence, by increasing arousal threshold. Whereas loss of function of Notch triggers a rebound quiescence by decreasing the arousal threshold (Singh et al., 2011). Therefore, it needs to be kept in mind that gain and loss of function of Notch activity, most likely through completely different mechanisms may, in the end, have a similar net effect on the animal behavior. On the other hand, in the work of Seugnet, the effects of Notch on sleep are attributed to Notch signaling in glia rather than in neurons of the Drosophila cortex (Seugnet et al., 2011). Whether glia-neuron communication through Notch has an effect at the network level to modulate sleep responses, remains to be established. We expect that this question will be resolved through the use of targeted conditional loss or gain of function models in flies and rodents. Nevertheless, the latter data raise the intriguing possibility of bidirectional signaling at synapses (Ascano et al., 
2003). Another evidence for a role of Notch signaling in circadian oscillations comes from a study in Drosophila. The authors showed that, upon olfactory learning, Notch activation in the Mushroom Bodies induces an ultradian oscillation of CREB hyperphosphorylation through PKC activity, which is essential for long-term memory (Zhang et al., 2013). The non-canonical interaction between PKC and Notch remains yet to be resolved mechanistically, but it underlines how the crosstalk between Notch and CREB may be instrumental to the role of Notch in memory. Indeed, it appears that CREB phoshophorylation through c-AMP and MAPK activation during REM sleep in mice is essential for memory consolidation after learning (Luo et al., 2013). The positive interaction between Notch and sleep therefore merits further investigation. For example, it will be of interest to know whether this interaction still takes place without prior induction of Notch during wakeful learning.

In neural development, Notch is viewed as a clock gene due to its self-perpetrating activity through the oscillatory expression of the Hes genes which trigger autoinhibitory loops essential in cell fate specification and somitogenesis (Leimeister et al., 2000; Takahashi, 2005). If Notch also behaves as a clock gene in the adult brain, it is possible that it acts first in Hebbian/non-canonical modality at local synapses contributing to memory formation following learning. Whereas, later on in the consolidation phase involving sleep, Notch canonical signaling may function as a synaptic scaling pacemaker by inducing network oscillations which entrain the memory network. In addition, non-canonical and canonical signaling may be temporally defined based on the possible competition of signaling modality as shown for Wnt signaling (Bryja et al., 2009; Gao and Chen, 2010). Pulse chase experiments monitoring Notch activity over the period of memory maturation are necessary to ultimately address these scenarios.

Altogether, from the works presented we conclude that despite there is no doubt about a significant contribution of Notch signaling in learning and memory, the underlying molecular mechanisms remain largely unresolved. Future studies using genomewide analysis and proteomics approaches will help identify transcriptional and non-transcriptional targets of Notch activity in memory encoding. We believe that shedding light on these mechanisms will help finally understand whether the Notch pathway is critically involved in the memory impairment observed in $\mathrm{AD}$ and whether it could be therapeutically targeted.

\section{Acknowledgment}

The authors thank Dr. Cedric Wesley for his precious feedback during the realization of this commentary.

\section{REFERENCES}

Alberi L, Chi Z, Kadam SD, Mulholland JD, Dawson VL, Gaiano N, Comi AM. 2010. Neonatal stroke in mice causes long-term changes in neuronal Notch-2 expression that may contribute to prolonged injury. Stroke 41:S64-S71.

Alberi L, Liu S, Wang Y, Badie R, Smith-Hicks C, Wu J, Pierfelice TJ, Abazyan B, Mattson MP, Kuhl D, Pletnikov M, Worley PF, Gaiano N. 2011. Activity-induced Notch signaling in neurons requires Arc/Arg3.1 and is essential for synaptic plasticity in hippocampal networks. Neuron 69:437-444.

Alberi L, Hoey SE, Brai E, Scotti AL, Marathe S. 2013. Notch signaling in the brain: In good and bad times. Ageing Res Rev 12:801-814.

Alberini CM. 2009. Transcription factors in long-term memory and synaptic plasticity. Physiol Rev 89:121-145.

Arumugam TV, Chan SL, Jo DG, Yilmaz G, Tang SC, Cheng A, Gleichmann M, Okun E, Dixit VD, Chigurupati S, Mughal MR, Ouyang X, Miele L, Magnus T, Poosala S, Granger DN, Mattson MP. 2006. Gamma secretase-mediated Notch signaling worsens brain damage and functional outcome in ischemic stroke. Nat Med 12:621-623.

Arumugam TV, Cheng YL, Choi Y, Choi YH, Yang S, Yun YK, Park JS, Yang DK, Thundyil J, Gelderblom M, Karamyan VT, Tang SC, Chan SL, Magnus T, Sobey CG, Jo DG. 2011. Evidence that gamma-secretase-mediated Notch signaling induces neuronal cell death via the nuclear factor-kappaB-Bcl-2-interacting mediator of cell death pathway in ischemic stroke. Mol Pharmacol 80:23-31.

Ascano JM, Beverly LJ, Capobianco AJ. 2003. The C-terminal PDZligand of JAGGED1 is essential for cellular transformation. J Biol Chem 278:8771-8779.

Berezovska O, Xia MQ, Hyman BT. 1998. Notch is expressed in adult brain, is coexpressed with presenilin-1, and is altered in Alzheimer disease. J Neuropathol Exp Neurol 57:738-745.

Berezovska O, Frosch M, McLean P, Knowles R, Koo E, Kang D, Shen J, Lu FM, Lux SE, Tonegawa S, Hyman BT. 1999. The Alzheimer-related gene presenilin 1 facilitates notch 1 in primary mammalian neurons. Brain Res Mol Brain Res 69:273-280.

Brai E, Marathe S, Zentilin L, Giacca M, Nimpf J, Kretz R, Scotti A, Alberi L. 2014. Notch1 activity in the olfactory bulb is odourdependent and contributes to olfactory behaviour. Eur J Neurosci 40:3436-3439.

Bryja V, Andersson ER, Schambony A, Esner M, Bryjová L, Biris KK, Hall AC, Kraft B, Cajanek L, Yamaguchi TP, Buckingham M, Arenas E. 2009. The Extracellular Domain of Lrp5/6 Inhibits Noncanonical Wnt Signaling In Vivo. Mol Biol Cell 20:924936.

Caroni P, Donato F, Muller D. 2012. Structural plasticity upon learning: Regulation and functions. Nat Rev Neurosci 13:478-490.

Chao MY, Larkins-Ford J, Tucey TM, Hart AC. 2005. lin-12 Notch functions in the adult nervous system of $C$. elegans. BMC Neurosci $6: 45$.

Cheng H-T, Kim M, Valerius MT, Surendran K, Schuster-Gossler K, Gossler A, McMahon AP, Kopan R. 2007. Notch2, but not Notch1, is required for proximal fate acquisition in the mammalian nephron. Development 134:801-811.

Conboy L, Seymour CM, Monopoli MP, O’Sullivan NC, Murphy KJ, Regan CM. 2007. Notch signalling becomes transiently attenuated during long-term memory consolidation in adult Wistar rats. Neurobiol Learn Mem 88:342-351.

Costa RM, Honjo T, Silva AJ. 2003. Learning and memory deficits in Notch mutant mice. Curr Biol 13:1348-1354.

Costa RM, Drew C, Silva AJ. 2005. Notch to remember. Trends Neurosci 28:429-435.

Dahlhaus M, Hermans JM, Van Woerden LH, Saiepour MH, Nakazawa K, Mansvelder HD, Heimel JA, Levelt CN. 2008. Notch 1 signaling in pyramidal neurons regulates synaptic connectivity and experience-dependent modifications of acuity in the visual cortex. J Neurosci 28:10794-10802.

Dias BG, Goodman JV, Ahluwalia R, Easton AE, Andero R, Ressler KJ. 2014. Amygdala-Dependent Fear Memory Consolidation via miR-34a and Notch Signaling. Neuron 83:906-918. 
Erickson JD, De Gois S, Varoqui H, Schafer MK-H, Weihe E. 2006. Activity-dependent regulation of vesicular glutamate and GABA transporters: A means to scale quantal size. Neurochem Int 48: 643-649.

Fan X, Mikolaenko I, Elhassan I, Ni X, Wang Y, Ball D, Brat DJ, Perry A, Eberhart CG. 2004. Notch1 and Notch2 Have Opposite Effects onEmbryonalBrain Tumor Growth. CancerRes64:7787-7793.

Ferrari Toninelli G, Bernardi C, Quarto M, Lozza G, Memo M, Grilli M. 2003. Long-lasting induction of Notch2 in the hippocampus of kainate-treated adult mice. Neuroreport 14:917-21.

Fioravante D, Byrne JH. 2011. Protein degradation and memory formation. Brain Res Bull 85:14-20.

Frank MG. 2012. Erasing Synapses in Sleep: Is It Time to Be SHY? Neural Plast 2012:e264378.

Fustiñana MS, Federman N, Freudenthal R, Romano A. 2014. Protein degradation by ubiquitin-proteasome system in formation and labilization of contextual conditioning memory. Learn Mem 21: 478-487.

Gal-Ben-Ari S, Kenney JW, Ounalla-Saad H, Taha E, David O, Levitan D, Gildish I, Panja D, Pai B, Wibrand K, Simpson TI, Proud CG, Bramham CR, Armstrong JD, Rosenblum K. 2012.ô Consolidation and translation regulation. Learn Mem 19:410-422.

Gao C, Chen Y-G. 2010. Dishevelled: The hub of Wnt signaling. Cell Signal 22:717-727.

Ge X, Hannan F, Xie Z, Feng C, Tully T, Zhou H, Zhong Y. 2004. Notch signaling in Drosophila long-term memory formation. Proc Natl Acad Sci U A 101:10172-10176.

Giniger E. 1998. A role for Abl in Notch signaling. Neuron 20: 667-681.

Giniger E. 2012. Notch signaling and neural connectivity. Curr Opin Genet Dev 22:339-346.

Han J-H, Kushner SA, Yiu AP, Cole CJ, Matynia A, Brown RA, Neve RL, Guzowski JF, Silva AJ, Josselyn SA. 2007. Neuronal competition and selection during memory formation. Science 316:457-460.

Herz J, Chen Y. 2006. Reelin, lipoprotein receptors and synaptic plasticity. Nat Rev Neurosci 7:850-859.

Kageyama R, Ohtsuka T, Shimojo H, Imayoshi I. 2008. Dynamic Notch signaling in neural progenitor cells and a revised view of lateral inhibition. Nat Neurosci 11:1247-12451.

Kyriazis GA, Wei Z, Vandermey M, Jo D-G, Xin O, Mattson MP, Chan SL. 2008. Numb endocytic adapter proteins regulate the transport and processing of the amyloid precursor protein in an isoform-dependent manner implications for alzheimer disease pathogenesis. J Biol Chem 283:25492-25502.

Leimeister C, Dale K, Fischer A, Klamt B, Hrabe de Angelis M, Radtke F, McGrew MJ, Pourquie O, Gessler M. 2000. Oscillating expression of c-Hey2 in the presomitic mesoderm suggests that the segmentation clock may use combinatorial signaling through multiple interacting bHLH factors. Dev Biol 227:91-103.

Li Y, Hibbs MA, Gard AL, Shylo NA, Yun K. 2012. Genome-wide analysis of N1ICD/RBPJ targets in vivo reveals direct transcriptional regulation of Wnt, $\mathrm{SHH}$, and hippo pathway effectors by Notch1. Stem Cells 30:741-752.

Lieber T, Kidd S, Struhl G. 2011. DSL-notch signaling in the drosophila brain in response to olfactory stimulation. Neuron 69:468-481.

Liu S, Wang Y, Worley PF, Mattson MP, Gaiano N. The canonical Notch pathway effector RBP-J regulates neuronal plasticity and expression of GABA transporters in hippocampal networks. Hippocampus (in press).

Luo J, Phan TX, Yang Y, Garelick MG, Storm DR. 2013. Increases in cAMP, MAPK Activity, and CREB Phosphorylation during REM Sleep: Implications for REM Sleep and Memory Consolidation. J Neurosci 33:6460-6468.

Marathe S, Alberi L. 2014. Monitoring notch activity in the mouse. Methods Mol Biol Clifton NJ 1187:115-129.

Matsuno M, Horiuchi J, Tully T, Saitoe M. 2009. The Drosophila cell adhesion molecule klingon is required for long-term memory formation and is regulated by Notch. Proc Natl Acad Sci U S A 106:310-315.

McGill MA, Dho SE, Weinmaster G, McGlade CJ. 2009. Numb regulates post-endocytic trafficking and degradation of notch1. J Biol Chem 284:26427-26438.

Miyashita T, Kubik S, Lewandowski G, Guzowski JF. 2008. Networks of neurons, networks of genes: An integrated view of memory consolidation. Neurobiol Learn Mem 89:269-284.

Moehlmann T, Winkler E, Xia X, Edbauer D, Murrell J, Capell A, Kaether C, Zheng H, Ghetti B, Haass C, Steiner H. 2002. Presenilin-1 mutations of leucine 166 equally affect the generation of the Notch and APP intracellular domains independent of their effect on Abeta 42 production. Proc Natl Acad Sci U S A 99:8025-8030.

Nishimura T, Yamaguchi T, Tokunaga A, Hara A, Hamaguchi T, Kato K, Iwamatsu A, Okano H, Kaibuchi K. 2006. Role of numb in dendritic spine development with a Cdc42 GEF intersectin and EphB2. Mol Biol Cell 17:1273-1285.

Oliva CA, Vargas JY, Inestrosa NC. 2013. Wnt signaling: Role in LTP, neural networks and memory. Ageing Res Rev 12:786-800.

O’Neill J, Pleydell-Bouverie B, Dupret D, Csicsvari J. 2010. Play it again: Reactivation of waking experience and memory. Trends Neurosci 33:220-229.

Ong C-T, Cheng H-T, Chang L-W, Ohtsuka T, Kageyama R, Stormo GD, Kopan R. 2006. Target selectivity of vertebrate notch proteins collaboration between discrete domains and csl-binding site architecture determines activation probability. J Biol Chem 281:5106-5119.

Pan Y, Liu Z, Shen J, Kopan R. 2005. Notch1 and 2 cooperate in limb ectoderm to receive an early Jagged2 signal regulating interdigital apoptosis. Dev Biol 286:472-482.

Parr C, Watkins G, Jiang W. 2004. The possible correlation of Notch1 and Notch-2 with clinical outcome and tumour clinicopathological parameters in human breast cancer. Int J Mol Med. Available from: http://www.spandidos-publications.com/ijmm/14/5/779.

Placanica L, Zhu L, Li Y-M. 2009. Gender- and age-dependent $\gamma$-secretase activity in mouse brain and its implication in sporadic Alzheimer disease. PLoS One 4:e5088.

Presente A, Boyles RS, Serway CN, de Belle JS, Andres AJ. 2004. Notch is required for long-term memory in Drosophila. Proc Natl Acad Sci U S A 101:1764-1768.

Saab BJ, Mansuy IM. 2014. Neuroepigenetics of memory formation and impairment: The role of microRNAs. Neuropharmacology 80: 61-69.

Sargin D, Botly LCP, Higgs G, Marsolais A, Frankland PW, Egan SE, Josselyn SA. 2013. Disrupting Jagged1-Notch signaling impairs spatial memory formation in adult mice. Neurobiol Learn Mem 103:39-49.

Sato C, Turkoz M, Dearborn JT, Wozniak DF, Kopan R, Hass MR. 2012. Loss of $\mathrm{RBPj}$ in postnatal excitatory neurons does not cause neurodegeneration or memory impairments in aged mice. PLoS One 7:e48180.

Saura CA, Choi S-Y, Beglopoulos V, Malkani S, Zhang D, Rao BSS, Chattarji S, Kelleher III RJ, Kandel ER, Duff K, Kirkwood A, Shen J. 2004. Loss of presenilin function causes impairments of memory and synaptic plasticity followed by age-dependent neurodegeneration. Neuron 42:23-36.

Seugnet L, Suzuki Y, Merlin G, Gottschalk L, Duntley SP, Shaw PJ. 2011. Notch Signaling modulates sleep homeostasis and learningô after sleep deprivation in drosophila. Curr Biol 21: 835-840.

Shepherd JD, Rumbaugh G, Wu J, Chowdhury S, Plath N, Kuhl D, Huganir RL, Worley PF. 2006. Arc mediates homeostatic synaptic scaling of AMPA receptors. Neuron 52:475-484.

Singh K, Chao MY, Somers GA, Komatsu H, Corkins ME, LarkinsFord J, Tucey T, Dionne HM, Walsh MB, Beaumont EK, Hart DP, Lockery SR, Hart AC. 2011. C. elegans notch signaling regulates adult chemosensory response and larval molting quiescence. Curr Biol 21:825-834. 
Song JK, Giniger E. 2011. Noncanonical notch function in motor axon guidance is mediated by Rac GTPase and the GEF1 domain of trio. Dev Dyn 240:324-32.

Song Q, Sun K, Shuai Y, Lin R, You W, Wang L, Zhong Y. 2009. Suppressor of hairless is required for long-term memory formation in Drosophila. J Neurogenet 23:405-411.

Steiner H, Duff K, Capell A, Romig H, Grim MG, Lincoln S, Hardy J, Yu X, Picciano M, Fechteler K, Citron M, Kopan R, Pesold B, Keck S, Baader M, Tomita T, Iwatsubo T, Baumeister R, Haass C. 1999. A loss of function mutation of presenilin-2 interferes with amyloid betapeptide production and notch signaling. J Biol Chem 274:28669-73.

Steiner H, Fluhrer R, Haass C. 2008. Intramembrane proteolysis by gamma-secretase. J Biol Chem 283:29627-31.

Stump G, Durrer A, Klein AL, Lutolf S, Suter U, Taylor V. 2002. Notch1 and its ligands Delta-like and Jagged are expressed and active in distinct cell populations in the postnatal mouse brain. Mech Dev 114:153-9.

Takahashi Y. 2005. Common mechanisms for boundary formation in somitogenesis and brain development: Shaping the "chic" chick. Int J Dev Biol 49:221-30.

Trimarchi T, Bilal E, Ntziachristos P, Fabbri G, Dalla-Favera R, Tsirigos A, Aifantis I. 2014. Genome-wide mapping and characterization of notch-regulated long noncoding RNAs in acute leukemia. Cell 158:593-606.

Wang H, Zou J, Zhao B, Johannsen E, Ashworth T, Wong H, Pear WS, Schug J, Blacklow SC, Arnett KL, Bernstein BE, Kieff E,
Aster JC. 2011. Genome-wide analysis reveals conserved and divergent features of Notch1/RBPJ binding in human and murine T-lymphoblastic leukemia cells. Proc Natl Acad Sci 108: 14908-14913.

Wang Y, Chan SL, Miele L, Yao PJ, Mackes J, Ingram DK, Mattson MP, Furukawa K. 2004. Involvement of notch signaling in hippocampal synaptic plasticity. Proc Natl Acad Sci USA 101: 9458-9462.

Wu J, Petralia RS, Kurushima H, Patel H, Jung M, Volk L, Chowdhury S, Shepherd JD, Dehoff $\mathrm{M}$, Li Y, Kuhl D, Huganirô RL, Price DL, Scannevin R, Troncoso JC, Wong PC, Worley PF. 2011. Arc/Arg3.1 regulates an endosomal pathway essential for activity-dependent $\beta$-amyloid generation. Cell 147: 615-628.

Yoon KJ, Lee HR, Jo YS, An K, Jung SY, Jeong MW, Kwon SK, Kim NS, Jeong HW, Ahn SH, Kim KT, Lee K, Kim E, Kim JH, Choi JS, Kaang BK, Kong YY. 2012. Mind bomb-1 is an essential modulator of long-term memory and synaptic plasticity via the Notch signaling pathway. Mol Brain Int 5:40.

Young EJ, Williams CL. 2013. Differential activation of amygdala Arc expression by positive and negatively valenced emotional learning conditions. Front Behav Neurosci 7:191.

Zhang J, Little CJ, Tremmel DM, Yin JCP, Wesley CS. 2013. Notch-inducible hyperphosphorylated CREB and its ultradian oscillation in long-term memory formation. J Neurosci 33: 12825-12834. 